\title{
Digital Industrial Platforms
}

\author{
Tobias Pauli · Erwin Fielt • Martin Matzner
}

Received: 18 December 2019/Accepted: 7 December 2020/Published online: 12 January 2021

(C) The Author(s) 2021

Keywords Digital platform · IIoT platform · Platform ecosystem · Marketplace $\cdot$ Business-to-business $\cdot$ Internet of things · Industrial internet of things · Industry 4.0 . Manufacturing

\section{Introduction}

With digitalization ongoing, there is no end in sight for the advance of the platform economy (Parker et al. 2016) as platforms and distributed innovation are among the main trajectories for digital innovation (Yoo et al. 2012). Within the information systems field, the primary type of platforms studied are digital, software platforms, that is, "the extensible codebase of a software-based system that provides core functionality shared by apps that interoperate with it, and the interfaces through which they interoperate" (Tiwana 2014, p. 7). Besides established domains for digital platforms such as enterprise software and mobile communication, many other domains are currently undergoing "platformization". In their efforts to implement

Accepted after two revisions by Ulrich Frank.

T. Pauli · M. Matzner $(\square)$

Chair of Digital Industrial Service Systems, Friedrich-

Alexander-Universität Erlangen-Nürnberg, Fürther Straße 248, 90429 Nuremberg, Germany

e-mail: martin.matzner@fau.de

T. Pauli

e-mail: tobias.pauli@fau.de

\section{E. Fielt}

School of Information Systems, Queensland University of Technology, 2 George Street, Brisbane, Australia

e-mail: e.fielt@qut.edu.au
Industry 4.0, an increasing number of industrial firms are establishing their own digital platforms, such as Siemens' MindSphere, General Electric's (GE) Predix, or Bosch's IoT Suite. However, these industrial incumbents are not the only ones venturing into the market of digital industrial platforms. Platform- or Infrastructure-as-a-Service (PaaS/ IaaS) providers such as Amazon Web Services (AWS) or Microsoft Azure are also moving into the manufacturing domain, offering their own platforms or providing infrastructure, services, and technologies to other platforms.

Digital industrial platforms act as both innovation and transaction platforms (Cusumano et al. 2020). First, they allow for the collection and analysis of data from a variety of industrial assets and devices, ranging from tools and machines to vehicles or whole warehouses and factories. This data is usually made available to an ecosystem of third-party firms, who can build complementary solutions such as industrial applications and services. Second, many of the platforms offer marketplaces to facilitate the distribution and use of the created applications to a large market of industrial customers. Thus, digital industrial platforms are an important building block for Industry 4.0, which has been affecting the manufacturing industry for the past few years (Lasi et al. 2014). Currently, however, firms are facing significant challenges in their establishment (Marx 2020).

While (digital) platforms in general have been a prominent topic in BISE research, the rise of digital industrial platforms raises some new, important questions: What are the key characteristics of these platforms? How are they similar or different to other kinds of platforms, in particular as studied in the information systems discipline? What are the implications for research and practice, in particular the BISE research community? In this catchword, we provide tentative answers to these questions 
along two dimensions: a technical perspective focusing on the architectural complexity of the industrial platforms themselves, and a market perspective focusing on the organizational complexity of the business-to-business context. Based on the described peculiarities of digital industrial platforms, we subsequently discuss areas for research that are especially relevant for the BISE research community.

\section{Digital Industrial Platforms}

Platforms are successful due to two central roles they can perform: acting as a technological foundation and as a market intermediary (Gawer 2014; Schreieck et al. 2016). From a technological perspective, innovation platforms enable the creation of complementary solutions by others. They do so by offering a stable core with standardized interfaces and boundary resources for third parties (Baldwin and Woodard 2009; Ghazawneh and Henfridsson 2013). From a market intermediary perspective, transaction platforms facilitate interactions between different groups of actors, such as providers of applications (as sellers) and users (as buyers), by offering a marketplace (Parker et al. 2016). Platforms often jointly play both of these roles, as is also the case for digital industrial platforms.

The idea behind digital industrial platforms is to collect and integrate industrial asset data centrally and leverage this data for the creation of smart applications and services with the help of complementors (Beverungen et al. 2019; Schermuly et al. 2019). Figure 1 depicts the multi-layered architecture of a digital industrial platform. The platform itself is positioned on the service layer, in reference to the IoT stack or the layered modular architecture of digital innovation (Yoo et al. 2010; Sisinni et al. 2018). Consequently, the platform usually performs the role of an "integration middleware" (Guth et al. 2016, p. 2), in the sense of offering data storage and processing capabilities as well as an operating system for applications (Hodapp et al. 2019b). Thus, broadly speaking, the platform acts as a bridge between industrial assets and applications (Wortmann and Flüchter 2015).

Below the platform or service layer are the device and connectivity layers. The former comprises all physical assets and devices, more specifically their sensors for data capture and actuators. The latter comprises everything necessary for transferring the sensor data to the platform, but also transferring data back to provoke actions by the machines. More specifically, it comprises connectivity technologies such as Ethernet or $5 \mathrm{G}$, communication protocols such as Message Queueing Telemetry Transport (MQTT), but also gateways that can handle these standards and maybe even possess edge computing capabilities for low latency applications. The application layer is located on top of the platform or service layer. Here, applications that use the previously collected data are developed.

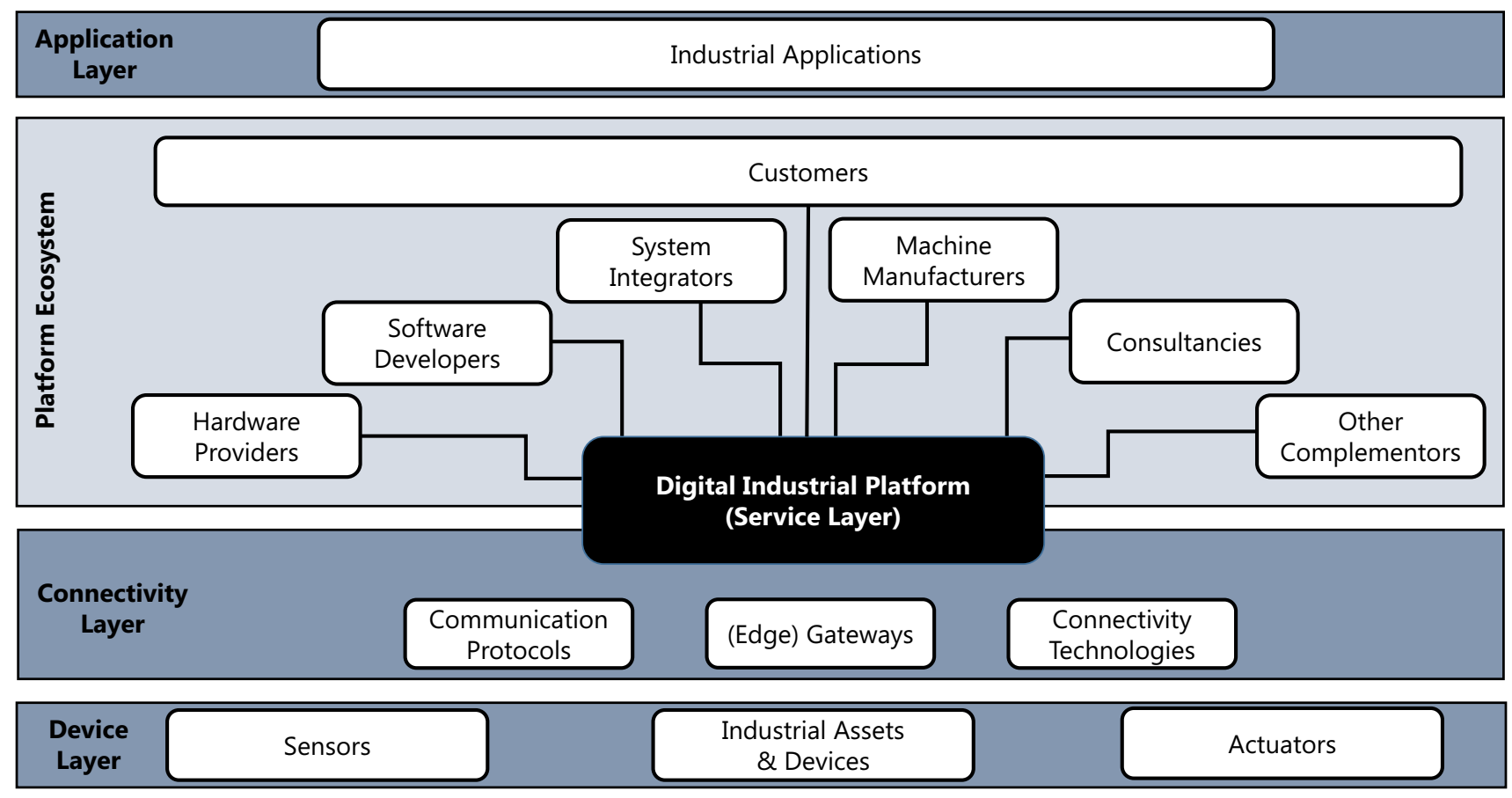

Fig. 1 Architecture of digital industrial platforms (based on Yoo et al. 2010; International Communications Union 2012; Guth et al. 2016; Sisinni et al. 2018) 
Typically, the data are not only used by a single party, but an ecosystem of complementors and customers (Petrik and Herzwurm 2020).

The emergence of digital industrial platforms is enabled by advances in a mix of technologies such as cloud computing, edge computing, big data analytics, and artificial intelligence, fueling the advancement of the (Industrial) Internet of Things (IoT). Therefore, what we call digital industrial platforms is referred to as IoT platform (Hodapp et al. 2019a; Hanelt et al. 2020) or IIoT platform (Schermuly et al. 2019; Petrik and Herzwurm 2020) by some researchers. However, these terms are often associated with a narrow focus on technical characteristics while the notion of digital platforms typically extends to the value enabled by the underlying technologies. Given the various technologies involved and the far reaching business opportunities enabled by the phenomenon, we deliberately chose digital industrial platform as a broader, more inclusive term in reference to the Federation of German Industries (BDI 2018).

We argue that the peculiarities of digital industrial platforms require a unique term and definition to reduce the conceptual ambiguity that has been criticized in research on digital platforms (De Reuver et al. 2018). The starting point of our definition is the definition of IoT platforms by Hodapp et al. (2019b, p. 2) as "a specific type of digital platforms that are (i) operated in a cloud or local environment, (ii) enable the interaction between smart objects and end-users (iii) by providing a core functionality to third-party developers to support the development of modular applications (iv) based on an abstraction service that is integrating underlying infrastructure and different data sources".

However, digital industrial platforms possess characteristics that are more similar to the concept of the IIoT, that is, the application of IoT-related technologies in an industrial environment (Boyes et al. 2018), which are not reflected in this definition. First, while the aforementioned definition mentions "smart objects", it is important to note that, in the context of digital industrial platforms, these objects are a heterogeneous set of industrial assets. Second, they operate in a complex business-to-business (B2B) environment, which means that the "end-users" are industrial firms instead of consumers. Third, as evident from Fig. 1, they rely on a considerably more diverse set of actors necessary for value creation than "developers". Fourth, importantly, "applications" are typically developed with the intent to purposefully influence the operation of the underlying industrial devices.

Thus, based on the discussion above, we define digital industrial platforms as platforms that (i) collect and integrate data from a heterogeneous set of industrial assets and devices, (ii) provide this data and additional technological support to an ecosystem of third-party organizations who develop and enable complementary solutions that (iii) affect the operation of industrial assets and devices, and (iv) provide a marketplace to facilitate interactions between platform owner, third-parties and business customers. In the following, we describe the peculiarities of digital industrial platforms in more detail. More specifically, we argue that - as a result of these peculiarities - they are characterized by high complexity, both from a technical and organizational perspective.

\section{Technical Perspective: The Architectural Complexity of Digital Industrial Platforms}

The architecture of a platform refers to how its components relate to and interact with each other (Baldwin and Woodard 2009). Digital industrial platforms display a more complex architecture than many platforms studied to date. In line with the multi-layered architecture of digital industrial platforms depicted in Fig. 1, with the platform itself as a service layer performing a connecting role between devices and applications, this architectural complexity can be analyzed from two sides: upstream, which is how data is collected and transferred, and downstream, which is how data is used by applications and services.

Typically, "platform architectures are united in that they partition a system into low- and high-variety components" (Baldwin and Woodard 2009, p. 26). While the platform core is standardized, variety is introduced in the peripheral modules to serve heterogeneous user needs. The core elements often refer to standardized hardware, for example, the iPhone in the case of iOS, or the PlayStation as a video game platform. Of course, there is often still some variety in the core components, such as the various smartphones that run Android, or the different CPUs or graphics cards in computers. However, industrial assets and devices are significantly more complex and heterogeneous, ranging from laser cutting machines, to furnaces, to ships, to whole factories, for example (Sisinni et al. 2018; Udoh and Kotonya 2018). Additionally, in contrast to smartphones, for example, industrial assets are not specifically built for specific platforms due to the rather long investment cycles of up to several decades in the industrial domain and the recent emergence of digital industrial platforms.

To overcome heterogeneity, platform architectures usually rely on standardized interfaces (Baldwin and Woodard 2009). Indeed, mitigating the issue of heterogeneity by facilitating interoperability is one of the central ideas behind digital industrial platforms. However, there is still considerable heterogeneity not only in terms of devices but across all layers of the architecture. In many areas, there is no universally accepted standard yet, leading to a 
variety of connectivity technologies (e.g., WiFi HaLow, IO Link, BLE) and communication protocols (e.g., MQTT, CoAP, OPC UA) that are sometimes even specified for single industries (e.g., umati as a companion specification of OPC UA for machine tools). This variety of communication and networking protocols, and data formats is often cited as one of the key challenges in solution development in the industrial domain (Bandyopadhyay and Sen 2011; Udoh and Kotonya 2018; Asemani et al. 2019; Hodapp et al. 2019a; Khan et al. 2020).

Downstream, the collected data is used to create applications and smart services that optimize industrial operations and provide new services. Again, as a result of the abovementioned heterogeneity, complementary solutions face a diverse set of assets deployed in various environmental conditions and settings. This is important, as it implies that digital industrial platforms do not only face the issue of integrating heterogeneous data, but also that the developed solutions need to act on physically heterogeneous devices (Mineraud et al. 2016). Imagine solutions aimed at improving the operation of complex industrial production lines. Each customer will have different machines in different configurations, connected to different information systems and operating in conjunction with other assets, most of which may not even be "smart".

As a result, no two deployment scenarios will be the same, leading to a focus on individual instead of generic solutions (Pauli et al. 2020). Importantly, as previously discussed, variety in the peripheral modules is a tenet of platforms. However, in domains such as ERP, the individual peripheral solutions are nevertheless designed to comprehensively serve a certain niche or vertical in a standardized manner. In contrast, the prevalence of customer-specific solutions we currently see on digital industrial platforms somewhat collides with the goal of platforms to efficiently address a heterogeneous market (Wareham et al. 2014).

Lastly, as applications on digital industrial platforms affect critical business processes, the requirements regarding reliability are very high (Sisinni et al. 2018). Furthermore, while data privacy and security are important issues in the context of B2C platforms, it is even more critical in the B2B domain (Khan et al. 2020). In a B2B context, where leaked data about critical business processes can be a significant threat to a firm's competitive advantage and reputation, data privacy and security are main concerns for customers. This entails two consequences. First, the development of industrial platform-based solutions typically requires significantly higher effort than the development of B2C mobile applications, for example. Second, complementors are facing adoption insecurity, as potential customers still have reservations regarding data-driven solutions affecting critical business processes, especially if the return-on-investment is not clear (Hodapp et al. 2019b; Pauli et al. 2020).

\section{Market Perspective: The Organizational Complexity of Digital Industrial Platforms}

Besides their technical complexity, digital industrial platforms also display higher organizational complexity compared to many other types of platforms. Based on their ability to attract third-party actors, platforms create ecosystems in the form of the "collection of firms interacting with a contribution to the complements" (De Reuver et al. 2018, p. 127). In particular, the integration of thirdparty solutions provided by complementors into the customers' operations and processes, involving hardware in the form of various industrial assets, and legacy infrastructure, creates a need for a diverse set of actors in the ecosystem (Papert and Pflaum 2017; Hein et al. 2019; Petrik and Herzwurm 2020). Typically, these actors include machine manufacturers, other hardware suppliers (e.g., sensor manufacturers), software developers, system integrators, and consultancies. Furthermore, for digital industrial platforms, all actors are specifically organizations whereas for many more well-known platforms (e.g., Apple's iOS, Google's Android, Uber and Airbnb) the customers are mainly individuals (that is consumers). This comes with several implications related to marketing and sales processes, and inter-organizational relationships.

Marketing and sales to business customers, such as industrial organizations, is significantly different from the processes in the B2C domain (Brennan 2014). As it interacts with the customer's buying process, selling products and services is usually more complex and may involve detailed technical proposals, extensive negotiation, and long-term relationship building. The purchase of a predictive maintenance solution, for example, will not be the responsibility of a single person or even department responsible for maintenance. Instead, it will require crossfunctional decision-making involving, among others, purchasing, finance, administration and engineering functions.

This indicates that purchasing industrial platform-based solutions will be not as straight forward as downloading an app from an app store, for example. Digital innovations come with much uncertainty and ambiguity (Kallinikos et al. 2013) making it hard to build a business case and having to compete with more traditional innovations that may be considered as "safer bets" (e.g., expected ROI) given the investments required. Importantly, the buyer may be specifying and designing the required product. This means that instead of an innovation push approach by the platform owner and complementors, the customer could demand a custom made or customized app and the use of a 
specific platform. In line with the technical heterogeneity, this leads to a focus on project-based and customer-specific solutions instead of generic offerings (Pauli et al. 2020). Professional purchasing departments will additionally be conscious about potential lock-in effects as a result of the high investments necessary (Schermuly et al. 2019).

Additionally, in a B2B context, the relationships between organizations and the networks in which these are embedded have to be taken into account. In the B2B domain, provider-customer relationships are shaped by repeated interactions between organizations and form a stable context in which sales and purchasing take place. Power, trust, and information sharing are important factors in these relationships (Brennan 2014). In addition, many organizations require prospective suppliers to go through a certification process and be added to a pool of accredited suppliers. Subsequently, the typical role of a transaction platform in the form of a market connecting many (unknown) sellers and buyers is less pronounced.

These relationships between firms are not only relevant for marketing and sales, but also for the establishment of digital industrial platforms in general. When building ecosystems around digital industrial platforms, platform owners leverage their existing relationships with other firms (Pauli et al. 2020). These relationships are typically hierarchically organized supply chains. In contrast, ecosystems are characterized by non-hierarchical relationships between actors (Jacobides et al. 2018; Kapoor 2018). Naturally, the transformation of relationships, from supplier to complementor, or from customer to partner, is challenging (Hanelt et al. 2020). Moreover, the introduction of a platform may have different positive and negative effects upon these actors, and as such the platform owner has to balance these diverse interests (Fielt et al. 2008).

\section{Implications for BISE Research}

As platforms in general have been primarily discussed in management literature, technological characteristics of different platforms have largely been abstracted with the result that "all technological platforms are treated as a homogenous group" (De Reuver et al. 2018, p. 127). However, as previously discussed, the interplay of technical and organizational complexity is critical for a meaningful analysis of digital industrial platforms. One could argue that exactly this interplay of technical and organizational elements makes digital industrial platforms predestined for analysis by the BISE research community, especially regarding its long-standing tradition of pursuing research with an impact in the industrial domain.

Thus, based on the characteristics of digital industrial platforms and their surrounding ecosystems, we derive implications for research in the form of a research agenda. To facilitate knowledge consolidation, we base our avenues for future research on the recently proposed research agendas on digital platforms by De Reuver et al. (2018) and digital platform ecosystems by Hein et al. (2020). More specifically, we select four areas that are affected by the peculiarities of digital industrial platforms according to recent studies: ecosystem building and network effects, complementor interaction and generativity, value capture and distribution, and the differences between industrial incumbents and native platform firms (Table 1).

\subsection{Ecosystem Building and Network Effects}

As a first avenue for digital platform ecosystem research, Hein et al. (2020) highlight means to attract complementors and ensure that they continuously engage with the platform. This is also highly relevant for digital industrial platforms. Given the nascent and rather fragmented market, the success of digital industrial platforms will to a great extent depend on their ability to attract an active ecosystem of actors (Wortmann and Flüchter 2015). However, motivating actors to join a platform ecosystem is one of the key challenges in platform establishment, often labeled as the "chicken-or-egg problem" (Caillaud and Jullien 2003; Tiwana 2014). It refers to the problem that users can only be attracted by a large number of providers of complements, while the providers of complements are only going to join a platform if there is a large customer base.

To overcome this problem, there are several different launch strategies, such as side switching, platform staging, or subsidizing (Stummer et al. 2018). These established strategies may not be applicable or may play out differently in the industrial domain. For example, a strategy such as side-switching, where the goal is to cover both the demand and supply side with the same group of actors "only works if services or products of both sides do not require high setup costs or specific knowledge" (Stummer et al. 2018, p. 171). As previously described, digital industrial platforms do not meet these requirements. Additionally, as many such platforms are established by incumbent industrial firms, they already have existing relationships with suppliers and customers. As a result, while many B2C platforms focus on the creation of a large (subsidized) customer base before addressing the business side (Muzellec et al. 2015), digital industrial platforms face different challenges. Thus, it will be critical to assess which known launch strategies can be transferred or adapted to digital industrial platforms and which new strategies platform owners employ to build their ecosystems. Notably, the challenge in this domain may not be the initial establishment of an ecosystem per se by attracting actors. Instead, in light of the existing (vertical) relationships with 
Table 1 A Research agenda for digital industrial platforms

\begin{tabular}{|c|c|}
\hline Avenue & Exemplary research questions \\
\hline \multirow[t]{2}{*}{$\begin{array}{l}\text { Ecosystem Building and Network } \\
\text { Effects }\end{array}$} & $\begin{array}{l}\text { Which strategies can digital industrial platforms employ to overcome the problem of attracting supply- and } \\
\text { demand-side actors? }\end{array}$ \\
\hline & How do network effects manifest in digital industrial platform ecosystems? \\
\hline \multirow[t]{2}{*}{$\begin{array}{l}\text { Complementor Interaction and } \\
\text { Generativity }\end{array}$} & $\begin{array}{l}\text { To which extent is the established idea of generativity transferable to complex domains such as digital } \\
\text { industrial platforms? }\end{array}$ \\
\hline & $\begin{array}{l}\text { How can platform owners overcome the technical and organizational barriers for generativity in digital } \\
\text { industrial platform ecosystems? }\end{array}$ \\
\hline \multirow[t]{2}{*}{ Value Capture and Distribution } & $\begin{array}{l}\text { What do feasible models for value distribution across all members of heterogeneous digital industrial } \\
\text { platform ecosystems look like? }\end{array}$ \\
\hline & $\begin{array}{l}\text { Which revenue streams can platform owners tap into to benefit from both innovation- and transaction-based } \\
\text { platform business models? }\end{array}$ \\
\hline \multirow[t]{2}{*}{$\begin{array}{l}\text { Industrial Incumbents vs. Platform } \\
\text { Natives }\end{array}$} & $\begin{array}{l}\text { How do the strategies for establishing digital industrial platforms differ between industrial incumbents and } \\
\text { native platform firms? }\end{array}$ \\
\hline & $\begin{array}{l}\text { How do industrial firms and large platform providers cooperate and compete on different layers of digital } \\
\text { industrial platforms? }\end{array}$ \\
\hline
\end{tabular}

other actors, launch strategies will need to provide answers as to how these connections can be effectively transformed into horizontal relationships.

In close relation to launch strategies, network effects as the underlying mechanism for attracting actors are another fruitful avenue for research on digital platform ecosystems. Such effects can be same-side (e.g., the more Facebook users, the higher the value for a single user) or cross-side (e.g., more app developers on iOS means more value for customers) (Rochet and Tirole 2003). As they enable rapid scaling, network effects are among the most important mechanisms for the success of platforms (van der Aalst et al. 2019). However, initial studies point toward a potentially lower importance of network-effects and a deviation from the typical winner-take-all phenomenon in the case of digital industrial platforms (Schermuly et al. 2019; Pauli et al. 2020).

In an industrial environment with high diversity in terms of application settings and customers with high bargaining power, customization will be inevitable in many cases, restricting the portability of applications (Saariko 2015; Udoh and Kotonya 2018; Schermuly et al. 2019). However, a large share of individual customer solutions by single complementors instead of a large variety of generic applications by a large ecosystem of third parties will negatively affect transaction leverage and cross-side network effects. At the same time, as complementors expect a consolidation of the market within the next years, a platform's strong market position is a critical factor for engaging with it (Pauli et al. 2020). This is especially important in light of the typically high investment needed to create solutions in this domain. Thus, it may also be too soon to dismiss winner-take-all dynamics altogether. In conclusion, the question of how network effects will manifest in digital industrial platform ecosystems is certainly worth investigating.

\subsection{Complementor Interaction and Generativity}

As another avenue for future research, Hein et al. (2020, p. 93) emphasize the question of how "different types of complementors interact with the digital platform to increase generativity". This touches upon two different aspects. First, how complementors interact with each other and the platform (owner). Given the various "different types of complementors" in digital industrial platform ecosystems, and the prevalently preexisting relationships between them and the platform owner, it will be interesting to see how this affects cooperative and competitive interactions.

Second, it raises the question of how generativity unfolds in digital industrial platforms. Digital platforms are frequently associated with generativity, that is, "a technology's overall capacity to produce unprompted change driven by large, varied, and uncoordinated audiences" (Zittrain 2006, p. 1980). In the case of platforms, this is often equated with the multitude of complementary innovations created by an ecosystem of actors. Generativity is, among other things, fueled by heterogeneity of resources (Yoo et al. 2010). Given the heterogeneity of industrial assets and devices that can be connected to digital industrial platforms and the ecosystem of actors that can in turn leverage this data to create a variety of solutions, it can be 
assumed that digital industrial platforms possess high generative potential.

However, there are also factors indicating that the generativity of industrial platforms may be more limited than in the case of other digital platforms (Pauli and Lin 2019). For one thing, the number of complementors can be expected to be much lower than in $\mathrm{B} 2 \mathrm{C}$ platforms due to the $\mathrm{B} 2 \mathrm{~B}$ setting and the required knowledge and resources for developing industrial solutions. Moreover, as digital industrial platforms operate in a more constrained environment, innovation by complementors may be subject to more control by the platform owner and specific requirements from the customer. Balancing control over thirdparties and their flexibility for innovating has always been a key challenge for platform owners (Wareham et al. 2014). In contrast to B2C platforms, the solutions developed on industrial platforms potentially affect processes critical for firms' success and may be subject to more stringent requirements for reliability and security.

Overall, it may be important to examine to which extent the established idea of generativity is transferable to more complex domains such as digital industrial platforms. More specifically, we argue that research on platform generativity in complex and constrained platform ecosystems such as in the case of digital industrial platforms needs to shift from treating generativity as an inherent capability to something that needs to be actively planned and facilitated (Marheine and Pauli 2020). In line with this, recent studies show that the range of boundary resources provided to third parties in digital industrial platform ecosystems to facilitate complementary innovation is larger than in many other domains, for example (Petrik and Herzwurm 2019).

\subsection{Value Capture and Distribution}

As a third avenue for research, we propose value capture and distribution among the different actors. Capturing an appropriate amount of value is a key challenge for platform owners in the design of platform business models (Schreieck et al. 2017). Many digital industrial platforms aspire to be both innovation and transaction platforms. However, initial empirical insights reveal that factors such as the heterogeneity of deployment environments, and the high effort for solution development in combination with complementors' insecurity regarding widespread adoption impede the transactional character of digital industrial platforms (Pauli et al. 2020). As complementors primarily develop individual, customer-specific solutions instead of generic solutions available to the whole ecosystem, the platform cannot act as a marketplace. Thus, while platforms studied to date often rely on transaction-based revenue models, such as retaining a percentage of every app sale, such approaches may not be feasible in the absence of generic solutions distributed over a central app store.

Research should therefore evaluate, which established revenue models platform owners can employ for digital industrial platforms, and which new revenue models may emerge in this domain. In initial studies, we currently see different approaches to mitigate the abovementioned issue, such as charging per API call or based on the amount of data traffic (Hodapp et al. 2019b). Additionally, more complex value capture mechanisms such as the absorption of complementary solutions by the platform owner are used (Pauli et al. 2020). However, such strategies bear the risk of negatively affecting the relationship with complementors, as studies from other domains have shown that the perceived threat of expropriation influences complementors' decision to affiliate with a platform (Huang et al. 2013).

Being attractive for complementors is a central issue, as platform ecosystems are characterized by horizontal relationships with no hierarchical control, and complementors can choose between different platforms. Thus, platform owners need to ensure that complementors' needs are considered in terms of value distribution across the ecosystem. In the case of digital industrial platforms with their heterogeneous ecosystems, this is even more critical as different types of complementors may vary considerably in their contributions and needs regarding value creation and capture. Establishing and orchestrating this ecosystem in a sustainable manner by providing each "side" with value capture mechanisms that allow them to benefit from participation is therefore a challenging task. Thus, research on digital industrial platforms needs to provide insights as to how platform owners can effectively create suitable mechanisms for value distribution among the different types of actors.

\subsection{Industrial Incumbents vs. Platform Natives}

As a final avenue for research, we propose the differences and coopetition between industrial incumbents and native platform firms. Given that established industrial firms (e.g., Siemens, Bosch, General Electric) as well as large platform providers (e.g., AWS, Microsoft) enter the market of digital industrial platforms, there are many intriguing questions in this regard for scholars and practitioners.

Industrial incumbents and platform natives will face different challenges when entering the market for digital industrial platforms. Hanelt et al. (2020) recently identified three major challenges industrial firms are facing when engaging in platform ecosystems: learning the new rules of platform ecosystem strategies, developing the internal readiness for platform ecosystems, and coping with the emerging hybridity challenge. The first two challenges refer to the necessary shift in thinking from a business 
model focused on product sales and value-adding services to a platform business model where the locus of innovation and value creation is shifted to external actors (Leijon et al. 2017). However, given the platforms' purpose to collect and aggregate data from physical industrial assets, incumbents will be forced "to always keep one foot in their established way of thinking and organizing" (Hanelt et al. 2020, p. 13). Thus, the third challenge stresses the need for business model portfolios and organizational ambidexterity, as the platform business extends these companies' existing business models, but does not replace them.

However, researchers should also examine the challenges native platform providers are facing when moving into the industrial domain. For example, given the complexity of industrial platform-based solutions, non-industrial platform firms need to cooperate with those from the industrial domain. Considering that critical factors influencing complementors' decision to engage with a specific digital industrial platform are the platform owner's background in the industrial domain, and a preexisting relationship with the platform owner, building large and diverse industrial ecosystems may be more difficult for native platform firms (Pauli et al. 2020).

Lastly, given that there is extensive cooperation between industrial incumbents and platform natives, it will be of interest to explore coopetition, that is, a simultaneous state of cooperation and competition (Bengtsson and Kock 2000). This is especially intriguing with regard to De Reuver et al.'s (2018) call for appropriate vertical scoping in digital platform research. Given the layered architecture of digital platforms, they can be studied on different levels. For example, while Siemens MindSphere is competing with AWS IoT or Microsoft Azure IoT, it uses their cloud computing services as technical infrastructure. Therefore, we call for the exploration of the different types of coopetition across the various layers of digital industrial platforms.

\section{Conclusion}

While the general rise of digital platforms is mirrored by an increasing research interest in the topic, research on digital industrial platforms is still scarce. It is broadly recognized that platforms cannot be treated as a homogenous phenomenon and choosing the right level of abstraction while embracing the individual complexity of platforms is necessary for a comprehensive analysis (Tilson et al. 2013). Thus, there is a growing understanding that digital platforms need to be analyzed differently from non-digital platforms (De Reuver et al. 2018). Similarly, we show that industrial platforms are different from many other digital platforms studied to date, such as mobile platforms (Basole and Karla 2010; Ghazawneh and Henfridsson 2013), internet platforms (Muzellec et al. 2015; Täuscher and Laudien 2018), or video game consoles (Cennamo and Santalo 2013; Cennamo et al. 2018; Ozalp et al. 2018). Lessons learned from other domains may therefore not always be readily transferable to industrial platforms, creating the need for novel insights into the mechanisms driving success and failure of industrial platforms (Schermuly et al. 2019).

However, not everything that looks new is completely new. Therefore, we can nevertheless build on the vast amount of insights on platforms in other domains. To successfully establish digital industrial platforms, practitioners must carefully evaluate which established strategies they can build on, which strategies they need to adapt to the new context, and which completely new strategies are required or become feasible. In this nascent domain, it is therefore important that the BISE research community provides practitioners with guidance. The complexities and implications presented herein can be a good starting point for the identification of phenomena that require further examination in the context of digital industrial platforms.

Funding Open Access funding enabled and organized by Projekt DEAL.

Open Access This article is licensed under a Creative Commons Attribution 4.0 International License, which permits use, sharing, adaptation, distribution and reproduction in any medium or format, as long as you give appropriate credit to the original author(s) and the source, provide a link to the Creative Commons licence, and indicate if changes were made. The images or other third party material in this article are included in the article's Creative Commons licence, unless indicated otherwise in a credit line to the material. If material is not included in the article's Creative Commons licence and your intended use is not permitted by statutory regulation or exceeds the permitted use, you will need to obtain permission directly from the copyright holder. To view a copy of this licence, visit http://creativecommons. org/licenses/by/4.0/.

\section{References}

Asemani M, Abdollahei F, Jabbari F (2019) Understanding IoT platforms: toward a comprehensive definition and main characteristic description. In: Proceedings of the 5th international conference on web research. Tehran, pp 172-177

Baldwin CY, Woodard CJ (2009) The architecture of platforms: a unified view. In: Gawer A (ed) Platforms, markets and innovation. Edward Elgar, Worcester, pp 19-44

Bandyopadhyay D, Sen J (2011) Internet of things: applications and challenges in technology and standardization. Wirel Pers Commun 58(1):49-69

Basole RC, Karla J (2010) On the evolution of mobile platform ecosystem structure and strategy. Bus Inf Syst Eng 3(5):313-322 
BDI (2018) German digital industry platforms. https://english.bdi.eu/ publication/news/german-digital-industry-platforms/. Accessed 12 Sep 2020

Bengtsson M, Kock S (2000) "Coopetition" in business networks - to cooperate and compete simultaneously. Ind Mark Manag 29(5):411-426

Beverungen D, Müller O, Matzner M et al (2019) Conceptualizing smart service systems. Electron Mark 29(1):7-18

Boyes H, Hallaq B, Cunningham J, Watson T (2018) The industrial internet of things (IIoT): an analysis framework. Comput Ind 101(1): $1-12$

Brennan R (2014) Business-to-business marketing. In: Alhajj R, Rokne J (eds) Encyclopedia of social network analysis and mining. Springer, New York, pp 83-86

Caillaud B, Jullien B (2003) Chicken \& egg: competition among intermediation service providers. Rand J Econ 34(2):309-328

Cennamo C, Santalo J (2013) Platform competition: strategic tradeoffs in platform markets. Strateg Manag J 34(11):1331-1350

Cennamo C, Ozalp H, Kretschmer T (2018) Platform architecture and quality trade-offs of multihoming complements. Inf Syst Res 29(2):461-478

Cusumano MA, Yoffie DB, Gawer A (2020) The future of platforms. MIT Sloan Manag Rev 61(3):46-54

De Reuver M, Sørensen C, Basole RC (2018) The digital platform: a research agenda. J Inf Technol 23(2):124-135

Fielt E, Janssen W, Faber E, Wagenaar R (2008) Design trade-offs for electronic intermediaries. Electron Mark 18(4):362-374

Gawer A (2014) Bridging differing perspectives on technological platforms: toward an integrative framework. Res Policy 43(7):1239-1249

Ghazawneh A, Henfridsson O (2013) Balancing platform control and external contribution in third-party development: the boundary resources model. Inf Syst J 23(2):173-192

Guth J, Breitenbücher U, Falkenthal M, et al (2016) Comparison of IoT platform architectures: a field of study based on a reference architecture. In: Cloudification of the internet of things (IEEE), Paris

Hanelt A, Nischak F, Markus N, et al (2020) Building platform ecosystems for IoT - exploring the impact on industrial-age firms. In: Proceedings of the 28th European conference on information systems, pp 1-17

Hein A, Weking J, Schreieck M et al (2019) Value co-creation practices in business-to-business platform ecosystems. Electron Mark 29(3):1-16

Hein A, Schreieck M, Riasanow T et al (2020) Digital platform ecosystems. Electron Mark 30(1):87-98

Hodapp D, Hawlitschek F, Kramer D (2019a) Value co-creation in nascent platform ecosystems: a delphi study in the context of the internet of things. In: Proceedings of the 40th international conference on information systems, Munich

Hodapp D, Remane G, Hanelt A, Kolbe LM (2019b) Business models for internet of things platforms: empirical development of a taxonomy and archetypes. In: Proceedings of the 14th international conference on Wirtschaftsinformatik. Siegen

Huang P, Ceccagnoli M, Forman C, Wu DJ (2013) Appropriability mechanisms and the platform partnership decision: evidence from enterprise software. Manag Sci 59(1):102-121

International Communications Union (2012) ITU-T Y.2060: Overview of the internet of things. ITU, Geneva

Jacobides MG, Cennamo C, Gawer A (2018) Towards a theory of ecosystems. Strateg Manag J 39(8):2255-2276

Kallinikos J, Aaltonen A, Marton A (2013) The ambivalent ontology of digital artifacts. MIS Q 37(2):357-370

Kapoor R (2018) Ecosystems: broadening the locus of value creation. J Organ Des 7(12):1-16
Khan WZ, Rehman MH, Zangoti HM et al (2020) Industrial internet of things: recent advances, enabling technologies and open challenges. Comput Electr Eng 81(1):1-12

Lasi H, Fettke P, Kemper H-G et al (2014) Industry 4.0. Bus Inf Syst Eng 6(4):239-242

Leijon E, Svenheden A, Svahn F (2017) Platform thinking in incumbent firms: from concept to capability. In: Proceedings of the 50th Hawaii international conference on system sciences. Big Island, pp 4766-4775

Marheine C, Pauli T (2020) Driving generativity in industrial iot platform ecosystems. In: Proceedings of the 41st international conference on information systems, India

Marx U (2020) Internet-plattformen: Der Maschinenbau hinkt digital hinterher. In: FAZ.NET. https://www.faz.net/aktuell/wirtschaft/ der-maschinenbau-hinkt-digital-hinterher-16958284.html. Accessed 20 Sep 2020

Mineraud J, Mazhelis O, Su X, Tarkoma S (2016) A gap analysis of internet-of-things platforms. Comput Commun 89-90:5-16

Muzellec L, Ronteau S, Lambkin M (2015) Two-sided internet platforms: a business model lifecycle perspective. Ind Mark Manag 45:139-150

Ozalp H, Cennamo C, Gawer A (2018) Disruption in platform-based ecosystems. J Manag Stud 55(7):1203-1241

Papert M, Pflaum A (2017) Development of an ecosystem model for the realization of internet of things (IoT) services in supply chain management. Electron Mark 27(2):175-189

Parker G, Van Alstyne MW, Choudary SP (2016) Platform revolution: how networked markets are transforming the economy and how to make them work for you. Norton, New York

Pauli T, Lin Y (2019) The generativity of industrial IoT platforms: beyond predictive maintenance? In: Proceedings of the 40th international conference on information systems, Munich

Pauli T, Marx E, Matzner M (2020) Leveraging Industrial IoT platform ecosystems: insights from the complementors' perspective. In: Proceedings of the 28th European conference on information systems. A Virtual AIS conference

Petrik D, Herzwurm G (2019) IIoT ecosystem development through boundary resources: a siemens mind sphere case study. In: Proceedings of the 2nd international workshop on softwareintensive business. Tallinn

Petrik D, Herzwurm G (2020) Towards the iIoT ecosystem development: understanding the stakeholder perspective. In: Proceedings of the 28th European conference on information systems. pp $1-15$

Rochet JC, Tirole J (2003) Platform competition in two-sided markets. J Eur Econ Assoc 1(4):990-1029

Saariko T (2015) Digital platform development: a service-oriented perspective. In: Proceedings of the 23rd European Conference on Information Systems. Münster

Schermuly L, Schreieck M, Wiesche M, Krcmar H (2019) Developing an industrial IoT platform: trade-off between horizontal and vertical approaches. In: 14th International conference on Wirtschaftsinformatik. Siegen

Schreieck M, Wiesche M, Krcmar H (2016) Design and governance of platform ecosystems: key concepts and issues for future research. In: 24th European conference on information systems. Istanbul

Schreieck M, Wiesche M, Krcmar H (2017) The platform owner's challenge to capture value: insights from a business-to-business IT platform. In: Proceedings of the 38th international conference on information systems, Seoul

Sisinni E, Saifullah A, Han S et al (2018) Industrial internet of things: challenges, opportunities, and directions. IEEE Trans Ind Informatics 14(11):4724-4734

Stummer C, Kundisch D, Decker R (2018) Platform launch strategies. Bus Inf Syst Eng 60(2):167-173 
Täuscher K, Laudien SM (2018) Understanding platform business models: a mixed methods study of marketplaces. Eur Manag J 36(3):319-329

Tilson D, Sørensen C, Lyytinen K (2013) Platform complexity: lessons from the music industry. In: Proceedings of the 46th Hawaii international conference on system sciences, Maui, pp 4625-4634

Tiwana A (2014) Platform ecosystems: aligning architecture, governance, and strategy. Morgan Kaufmann, Amsterdam

Udoh IS, Kotonya G (2018) Developing IoT applications: challenges and frameworks. IET Cyber-Phys Syst Theory Appl 3(2):65-72

van der Aalst W, Hinz O, Weinhardt C (2019) Big digital platforms. Bus Inf Syst Eng 61:645-648
Wareham J, Fox PB, Giner JLC (2014) Technology ecosystem governance. Organ Sci 25(4):1195-1215

Wortmann F, Flüchter K (2015) Internet of things: technology and value added. Bus Inf Syst Eng 57(3):221-224

Yoo Y, Henfridsson O, Lyytinen K (2010) The new organizing logic of digital innovation: an agenda for information systems research. Inf Syst Res 21(4):724-735

Yoo Y, Boland RJ, Lyytinen K, Majchrzak A (2012) Organizing for innovation in the digitized world. Organ Sci 23(5):1398-1408

Zittrain JL (2006) The generative internet. Harv Law Rev 119(7):1974-2040 